\title{
Analysis Diversity of Mangrove Plants and Brachyura (Uca Crab) at Yagasu Belawan Forest
}

\author{
Budianto $^{1}$, Edi Azwar ${ }^{2}$, Pandu Prabowo ${ }^{3}$, Abdurrozzaq Hasibuan ${ }^{4}$ \\ \{budianto@gmail.com ${ }^{1}$ \} \\ 1,2,3,4 Universitas Islam Sumatera Utara (UISU), Medan, Indonesia \\ 1,2,3 Department of Biology Education Faculty of Teacher Training and Education, Indonesia \\ ${ }^{4}$ Department of Industrial Engineering, Faculty of Engineering, Indonesia
}

\begin{abstract}
Mangrove is one of the ecosystems that need to be protected and conserved. If mangrove ecosystem is destroyed or damaged it will have a bad impact for the economy of people who live on the coast or mangrove waters. Uca Crab (Uca sp.) Itself is a small crab species that has a very important role in the balance of energy flows in the mangrove ecosystem. Uca Crabs also have many different genera and species. In the food chain, Uca $\mathrm{Crab}$ is the lowest consumer and detrivus in the food chain of mangrove ecosystems. For fishermen whose main livelihood is to sail and farmers of mangrove ponds of course the mangrove ecosystem is the main support that supports the livelihood. In relation to student lecture materials Such as the subject of Low Animals Taxonomy, animal ecology, plant ecology, and high plant taxonomy, it is necessary to have a direct study of the spaciousness which is the learning resource for the students. However, although this study is said to have great potential but is still limited to the ability, both financial and procedural abilities. Because this research is limited to Mangrove Yagasu Bagan Deli, District of Belawan Medan Fisherman Village With the potential of 23 Ha of Yagasu Forest selected as the location of the research object because of the unspoiled condition, protected, and positioned right on the expanse of the river mouth and the border with the east coast of Sumatra.
\end{abstract}

Keywords: $\quad$ Mangrove, Brachyura, Uca, Diversity, Yagasu

\section{Introduction}

Indonesia as the largest archipelago country has the largest mangrove forest in the world. in the world, which has 17.508 islands with a The world's mangrove forest reaches an area long coastline of $81,000 \mathrm{~km}$, has enormous of about 16.53 million hectares spread across coastal and marine resources potential. Asia 7,441,000 ha, Africa 3,258,000 ha and Indonesia is also an archipelagic country that US 5,831,000 ha, while in Indonesia it is reported to be $3,735,250$ ha. In the beginning almost the entire area of Bagan Deli Urban Village consists of mangrove forest ecosystem. However, along with the increase in population, so many residents from various regions migrate to the Village Bagan Deli so that the number of residents in Bagan Deli Village grew. In addition, the Bagan Deli Village includes the Malacca Strait international sea traffic area and has Belawan Harbor as an international port so that more and more people migrate and live in Bagan Deli Village. As a result there is a diversion of mangrove forest land and the utilization of mangrove forest resources on a large scale for the benefit of the population so that the ecosystem of mangrove forest is reduced. Therefore, the area of mangrove forest ecosystem in Bagan The mangrove forest ecosystem is complex and dynamic, but labile. It is said the complex because the ecosystem in addition to the mangrove vegetation, is also the habitat of various animals and aquatic biota. Uca Crabs 
have funny behaviors of eating, fighting and mating, all done at the same time. These crabs include small crabs (the biggest cuman about 2-3 cm) Like all crabs, Uca Crabs experience moulting or shell change as they grow (like a skin on a snake). In this moulting process, the claws and legs that have been broken before will reappear. Uca female crabs carry a collection of eggs on the lower side of his body and will settle in his burrow for two weeks. After that the female will try to get out to release her eggs into the tidal water. Eggs hatch into freeswimming larvae that drift with plankton, but transform into another form before settling and developing into Uca Crabs. Uca Crab is a detritivor. Small Uca Crab Captains take a piece of sediment from the ground and bring it to the mouth, then filter it.

\section{Research Metodology}

The procedures of Mangrove Diversity Identification and Uca Crab begins observes location or survey research location. Procedures of Mangrove Diversity Identification and Uca Crabs, namely; (1) Procedures for Identification of Mangrove Diversity and Uca Crab begins observation location or survey research location. Furthermore, field research based on research guides with key reference of mangrove and uca crab identification are as follows, (2) Identification of mangrove species in the research location. In the identification procedure of mangrove species, samples of mangrove trees such as leaves, flowers, and fruits obtained or collected are then collected, marked, and identified using the guidebooks of the morphology of (Noor and Khazali, 1999).

Sampling in this research was conducted using a research guide in which crab sampling was taken and identified by:

1. Crabs on the surface of the substrate were collected and collected in separate containers.

2. Crabs that are under the substrate (under the surface of the soil) are extracted by digging using a small shovel as deep as $10-15 \mathrm{~cm}$. Samples are then inserted into separate containers and grouped.

\subsection{Data Analysis}

Data analysis Types of Mangrove and Crab Uca Data Type Mangrove. The result of identification data of mangrove type done by descriptive analysis. Data of Uca Crab Diversity Conducted in descriptive analysis and using the following formula: a. Density (D). Density is the number of individuals of broad unity (Brower JE, Zar JH, 1990) with the following formula:

$X i=\frac{\mathrm{ni}}{\mathrm{A}}$

Description:

$\mathrm{Xi}=$ The density of the $\mathrm{nth}$ species, $\mathrm{Ni}=$ number of species ke $\mathrm{n}, \mathrm{A}=$ Surface area of sampling $(\mathrm{m} 2)$ b. Wealth Type (Species richness) To see species richness used Margalef index (1958), by formula: $\mathrm{R}=(S-1) / \ln (N)$ Information:

$\mathrm{S}=$ Total number of species $\mathrm{N}=$ total number of individuals c. Diversity (Diversity) Data processing of diversity used Shanon-Wiener index (1989) with the following formula:

$\mathrm{H}^{\prime}=-\Sigma(\mathrm{Pi} \ln \mathrm{Pi})$

$$
i=1
$$


Where:

$\mathrm{H}=$ diversity index

$\mathrm{Pi}=(\mathrm{ni} / \mathrm{N})$

$\mathrm{N}=$ Total number of all individuals of all species

$\mathrm{S}=$ Number of species

Criteria: The results of diversity ( $\mathrm{H}^{\prime}$ ) according to Barus (2001) are as follows:

$\mathrm{H}^{\prime}<1=$ low diversity (unstable)

$1<\mathrm{H}^{\prime}<1=$ Medium (normal) diversity

$\mathrm{H}^{\prime}>3=$ high diversity (stable)

\subsection{Data Analysis of Mangrove Types}

From field observations, there are 12 true mangrove species that have been discovered and analyzed. 12 Species include Rhizopora apiculata, Avicennia alba, Exoecaria agallocha, Nypa fructicans, Acantus ilicifolius, Acrostichum aureum, Morinda citrifolia, Hibiscus tiliaceus, Plucea indica, Rhizopora mucronata, Avicennia officinalis, and Bruguiera sexangula. Description of mangrove species based on station and number of samples obtained. The constituent substrate includes 1) Soil, 2) Sand and mud 3) sandy soil mixed with muddy soil. Where the stations are also divided into 2 conditions namely 1) exposed to high tide and 2) dry or not exposed to sea tide. From the results of observations in the field, the type of mangrove in each research station is not the same.

At station 1 found 4 types of true mangroves namely Rhizopora apiculata, Avicennia Alba, Exoecaria agallocha, and Nypa fructicans. There are five types of mangrove follow-up Acanthus ilicifolius, Acrostichum aureum, Morinda citrifolia, Hibiscus tiliaceus, and Plucea indica. In general, the mangrove contained in station 1 is the result of planting (reforestation) by the local community of Fisherman Village. At station 2 found 2 types of true mangrove that is Exoecaria agallocha, and Avicennia alba. and 1 type of mangrove followed by Acrostichum aureum. In general, mangrove grown in station 2 is a mangrove that grows wild. At station 3 found 7 types of true mangrove (Rhizopora apiculata, Rhizopora mucronata, Avicennia alba, Avicennia officinalis, Bruguiera sexangula, Exoecaria agallocha, and Nypa fructicans) and 2 types of mangrove follow-up Acrostichum aureum and Acanthus ilicifolius. Mangrove where the result of identification data of mangrove type done by descriptive analysis.

\section{a. Samples of three Mangroves Identified in The Research Sites}

\section{Rhizopora apiculata}

Trees with a height of $30 \mathrm{~m}$ with a trunk diameter of $50 \mathrm{~cm}$. It has a typical roar that reaches a height of 5 meters, and sometimes has roots out of the branch. The bark is dark grayand fickle. Leaf : Dark Skin, dark green with light green on the middle and redness at the bottom. The leaf strap is $17-35 \mathrm{~mm}$ long and the color is reddish. Unit and layout are simple and opposite. The shape of the ellipseis narrowed. Edge tapered. Size 7-19 x 3,5 $-8 \mathrm{~cm}$. Biseksual flowers, yellowish flower heads located on the handle $<14 \mathrm{~mm}$. Location in te armpits of leaves. Group formation is 2 flowers per group. The leaves are 4 yellow-white, no hair, 9-11 mm long. The petals of 4 yellow are brownish, curved. 11-12 stamen is not stemmed. Rough-shaped fruit is round to pear-like, brown, $2-3,5 \mathrm{~cm}$ long, containing one fertile seed.Hypocotyl cylindrical, doted, orange green. The cotyledone neck is red when it is ripe. Hypocotyle size 18-38 long and 1-2 cm diametre. Ecology : Grows on muddy soil, smooth inside and inundated during normal tide. Dislikes harder substrates mixed with sand. The level of dominance can reach $90 \%$ and vegetation growing in a location. 


\section{Avicennia alba}

The grove or the growing tree spreads with a height of $25 \mathrm{~m}$. The collection of trees forms a horizontal root system and a complex root of breath. The root of the breath is usually thin, finger-shaped (or like asparagus) covered by lenticels. Large bark grayish or dark brown, some overgrown, while others sometimes have smooth surfaces. In the old stems, sometimes found thin powder. Leaves : Smooth surface, shiny green top, pale bottom, unit and simple and opposite position. Lance shapes (such as akasia leaves) are sometimes elliptical. Tip tapered, size $16 \times 5 \mathrm{~cm}$. Flowers such as trident with a flower horde (yellow) almost along the segment of the bunch. Location at the end of the flower stalk. Grain formation $(10-30$ flowers per cluster). Crown leaves 4, bright yellow, 3-4 mm. Flower petals 5, stamens 4, fruit like cones, light yellowish green size $4 \times 2 \mathrm{~cm}$. Ecology : It is a pioneer species in mangrove swamp habitats in sheltered coastal locations as well as in the more salty parts along the tidal influenced river banks, as well as long the coastline. They generally like the front of the bay.

\section{Exoecaria agallocha}

Small moult tree with a height of 15 meters. The bark is gray, smooth, but has nodules. The roots spread along the surface of the soil, often tangled and covered by lenticels. Stems, branches and leaves have a sap (shite and sticky) that can irritate the skin and eyes. Leaf: The greens is old and will turn red before bricking. The edges are serrated, there are 2 glands at the base of the leaf. Units and location are simple, crossed. Elliptical shape. Edge tapered, size 6.5 - 10,5 x $3.5-5 \mathrm{~cm}$. Flowers have either male or female flowers, never both. Male flowers (without handles) are smaller than females, and spread throughout the bunch. The male flower bunches are smelly, scattered, green and reach $11 \mathrm{~cm}$ in length. Located in the armpits of the leaves. Yellowish green petals. 3 yellow stamens. Fruit shaped like a ball with 3 bulges, green color, surfac like skin, contains dark brown seeds. Size of 5-7 mm diametes.

\subsection{Data Analysis Of Brachyura (Uca Spesies - Fiddler Crabs)}

In total there are 7 species of Brachyura crabs and are divided into 3 families (Ocypodidae, Grapsidae, and Sesarmidae) which are found and identified at the three specified stations. At Station 1 (Locals residential area) found 3 species of Uca annulipes, Uca tetragonon, and Metopograpsus oceanicus. At Station 2 (Area along the river banks) found 6 species namely Uca urvillei, Uca annulipes, Uca vocans, Uca drussuimeri, Metopograpsus oceanicus, and Sesarma villosum. At station 3 (Mangrove Forest area "YAGASU") found 6 species namely Uca urvillei, Uca annulipes, Uca vocans, Uca drussuimeri, Uca tetragonon, and Metopograpsus oceanicus. From the results of sampling and identification it is seen that Uca annulies are present in all three stations. this indicates that this species is at the peak of the Brachyura macrobentos distribution, among the existing Ocypodidae Family. In general, Ocypodidae Family has a characteristic that is happy to live in areas with higher water content. While muddy substrate stations, both clay mud and sediment (mixed sludge) are ideal places for Uca crab to breed. Some other species of Uca crabs are rarely encountered in local populations due to their unnatural, dry, polluted, and so on. Almost all families of uca crab species live on muddy substrates with moisture content of $80-95 \%$. This is the main reason why the stations II and III are more varied. Unlike the Ocypodidae Family, the Grapsidae and Sesamidae Families tend to adapt more to the surrounding environment. The Grapsidae family rarely has a house or permanent residence. They prefer to be alone or in silence and hide behind the darkness. Species of the Grapsidae Family are very sensitive to sunlight. preferring 
to hide in areas where the sun's intensity is a bit like in the rocks, the lumber of the shady mangrove trees, or the mangrove roots that are protected from the sun's rays.

Meanwhile, Family Sesarmidae is a family of crab walkers, almost in all types of mangrove substrates can be found species of crabs Sesarma sp. The Sesarmidae family is also a reliable swimmer, although it has no swimming legs. Sesarmidae can swim very quickly and even faster than Crab Family Grapsidae. The sesarmidae family is basically a fan of muddy substrates with moisture content above $80 \%$. The radical physical changes in ecosystems make them adapt more quickly and are remarkable to survive.

Samples of three Fiddler's identified in the Research Sites

1. Uca annulipes

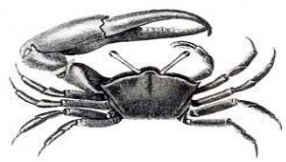

Fig. 1. Uca annulipes $1^{\text {st }}$

\section{Description :}

Lives in depth range based on 4 specimens in 3 taxa. Environmental ranges has depth range $(\mathrm{m}): 0,5-1 \mathrm{~m}$. Color has like porcelain fiddler prefer slightly sandier substrates. Uca annulipes tend ti live predominantly in habitats dominated by soft mud and many contain organic compounds. Bright colors mix between bright black and bright red is a special self that belongs to this species. Large claws are located on the left, and small claws are located on the right. In the process of fertilization, often lay eggs in nest, nests tend to be deeper when compared with other Uca species. The depth of the nest reaches 3 meters more, has an angles about 36 degrees. The nest factor is its adaptation to tidal tides.

\section{Uca drussuimeri}

This species has been founded on mud complex land with high salinity. Big and long right side giant claw, covered all front body and built up to fight and get couples. Has color that tends to be a bluish or reddish darkness on upper body part of the shell and down side of the body also. Black walking feet, pairs of foot and swimming legs are located on the 3th until 8th segment of the lateralis, eyeballs black solid and has red pupils. Crank stalk has a long thick stem.

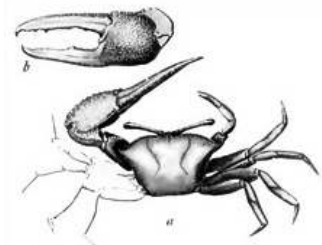

Fig. 2.Uca drussuimeri ${ }^{1 \text { st }}$

\section{Uca vocans}

Species live distilled subdivision of medium and moderate sedimentary sediment mud, has acolor that tends to be a bluish or greenish darkness on the upper body part of the shell. And tend to be lighter on the bottom, large claws are located on the right, bluish eyes with black pupils vertical lines. On the upper segment of the large white claws, and the bottom segment is reddish yellow (orange). Pairs of foot and swimming legs are located on the 10th segment on 
the lateralis, eyeballs have long stem. Crank stalk has a long shell so much sturdier than other Uca species, besides the size of the claw bigger also larger than the other Uca species.

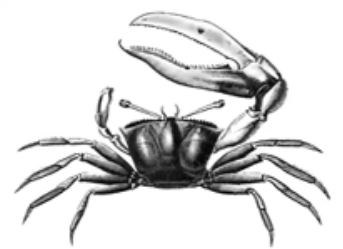

Fig. 3.Uca vocans ${ }^{1 \text { st }}$

\subsection{Data Analysis of Mangrove and Uca Diversity}

\subsubsection{Data Of Mangrove Species For Each Station}

Station 1 = Avicennia alba, Exoecaria agallocha, Nypa fructicans, Rhizopora apiculata, Acanthus ilicifolius, Acrostichum aureum, Morinda citrifolia, Hibiscus tiliaceus, Plucea indica, Station 2 = Avicennia alba, Exoecaria agallocha, Acrostichum aureum, Station $3=$ Avicennia alba, Avicennia officinalis, Bruguiera sexangula, Exoecaria agallocha, Nypa fructicans, Rhizopora apiculata, Rhizopora mucronata, Acanthus illicifolius, Acrostichum aureum

\subsubsection{Uca Crab Species Data at each station and its value}

Station 1 = Uca annulipes (Ocypodidae) collected 123, Uca tetragonon (Ocypodidae) collected 76, Metopograpsus oceanicus (Grapsidae) collected 36 Station $2=$ Uca annulipes (Ocypodidae) collected 75, Uca vocans (Ocypodidae) collected 45, Uca urvillei (Ocypodidae) collected 56, Uca drussuimeri (Ocypodidae),Metopograpsus oceanicus (Grapsidae) collected 44, Sesarma villosum (Sesarmidae), Station 3 = Uca annulipes (Ocypodidae) 173, Uca urvillei (Ocypodidae) 222, Uca drussuimeri (Ocypodidae) 129, Uca tetragonon (Ocypodidae) 245, Metopograpsus oceanicus (Grapsidae) 80, Sesarma villosum (Sesarmidae) 142.

With the total amount as follows :

- Uca annulipes $=$ total 453 heads

- Uca vocans $=$ total number 178 heads

- Uca urvillei $=$ total 222 heads

- Uca drussuimeri $=$ total number 129 heads

- Uca tetragonon $=$ total count of 245 heads

- Metopograpsus oceanicus $=$ total number 80 heads

- Sesarma villosum $=$ total of 142 heads

\subsection{The Index of Species diversity at each research station uses guidance reference field research Station 1:}

Uca annulipes

Amount $=123, \mathrm{Pi}=0.52, \mathrm{Ln} . \mathrm{pi}=-0.64, \mathrm{Pi}=-0.33, \mathrm{~S}=3.2$. Uca tetragonon Amount $=76, \mathrm{Pi}=$ $0.32, \mathrm{Ln} . \mathrm{Pi}=-1.12, \mathrm{Pi}=-0.36, \mathrm{~S}=3,3$. Metopograpsus oceanicus Amount $=36, \mathrm{Pi}=0.15$, Ln.Pi $=-1.87, \mathrm{Pi}=-0.28, \mathrm{~S}=3$ RESULT $:$ Amount $=235, \mathrm{Pi}=0.99, \mathrm{Ln} \cdot \mathrm{Pi}=-3.63, \mathrm{Pi}=-0.97$ 


\section{Result And Discussion}

\subsection{Mangroves}

Description of Mangrove Types From the observation in the field, the type of mangrove in each research station is not the same. At station 1 found four types of true mangrove (Rhizopora apiculata, Avicennia alba, Exoecaria agallocha, and Nypa fructicans) and five types of mangrove follow (Acanthus ilicifolius, Acrostichum aureum, Morinda citrifolia, Hibiscus tilliaceus, and Plucea indica L). In general, the mangrove contained in station 1 (Residential area of Fisherman Village Belawan Residents) is the result of planting (reforestation) by the local people of Kampung Nelayan. At station 2 found 2 types of true mangrove (Exoecaria agallocha and Avicennia alba) and 1 type of mangrove follow-up (Acrostihum aureum).

Here is a list of mangrove species found: Along the 2 mangrove stations found in general is a mangrove that grows wild, although it grows wildly. At station 3 found 7 species of true mangrove (Rhizopora apiculata, Rhizopora mucronata, Avicennia alba, Avicennia officinalis, Bruguiera sexangula, Exoecaria agallocha, Nypa fructicans) and 2 types of mangrove follow (Acrostihum aureum, Acanthus ilicifolius). Table List of Mangrove Types identified at Station 1 (Settlement Residents), Station 2 (along the banks of Bagan Deli), and Station 3 (Mangrove Forest Research Area YAGASU Deli Serdang District in April 2016.

No Type Mangrove

1. Avicennia alba

2. Avicennia efficinalis

3. Bruguiera sexangula

4. Exoecaria agallocha

5. Nypa fructicans

6. Rhizopora apiculata

7. Rhizopora mucronata

8. Alcanthus ilicifolius

9. Acrostichum aureum

10. Morinda citrifolia

11. Hibiscus tilliaceus

12. Plucea indica

Information:

$\wedge=$ True mangrove species $*=$ Type of mangrove follow-up In the table above shows a clear comparison of the mangrove species identified in the 3 types of stations. At station 1 where residence is located. From the observations it turns out that Avicennia alba species can adapt to salinity between $26-28 \%$ with dissolved oxygen content between 4.7-5.8 mg/l. This indicates that the Avicennia alba species have the most widespread adaptability to salinity and dissolved oxygen in other types of appeal. That's why Avicennia alba is in all stations. For Avicennia officinalis and Rhizopora sp. can adapt to salinity between $26-27 \%$ and dissolved oxygen content between $5.4-5.8 \mathrm{mg} / 1$ found in station III alone. This indicates environmental and natural factors both biotic and abiotic greatly affect the growth of mangroves. Mangrove is very sensitive to salinity. Various mangroves overcome salinity levels in different ways. Some are selectively capable of avoiding salt absorption from the growth medium, while some other species are capable of removing salts from specific glands in their leaves (Noor and Khazali, M., 1999). 
The types of crabs found at the study sites were Brachyura Crab (mangrove crab). Brachyura is found divided into 3 families namely Ocypodidae, Grapsidae, and Sesarmidae. An important role of mangrove crab in the mangrove ecosystem is as keystone species (dominant species). Among the many Brachyura families present, Uca crabs from the Ocypodidae family are the most dominant in the mangrove ecosystem. Characteristic of small stature, has a claw that is not the same size (one of them large) in the male species. And have both claws of the same size in the female species. Uca Crab is a unique crab. In addition to rapidly breeding, Uca crabs also have an attractive appearance. most of the Uca Crab family has a solid and colorful color. From this color difference Uca is also distinguished over species and genus. Meanwhile, Metopograpsus oceanicus was found at stations I and II. This type of crab is not a Uca crab family. This crab is a member of the "Climbers" crab family (Grapsid). Metopograpsus is a carnivorous crab and belongs to a true detrivum among crabs. The food is zooplankton and small fish. the bigger the size, the greater the prey he will eat. including into the families of cannibal crabs because they want to attack their younger neighbors. Metopograpsus is a predator crab. The uniqueness is fun to hide in the dark because this species is very sensitive to sunlight. In general, Metopograpsus is a hunter at night. Very happy to cluster somewhere. The obvious feature of Metopograpsus is the bluish-black body color in the dorsal and purple parts of the ventral part. If Metopograpsus feels threatened then he will raise both claws openly for self-defense and will not be afraid to strike back even though his predatory body size has a larger size than his body.

\subsection{Uca Crab Diversity Index}

In this study the value of the diversity of crab obtained at Station I of 1.73. At Station II 1.58. and at Station III of 0.99. This gives a final conclusion that in a state of being or normal. Type diversity is a combination of the number of species and the number of individuals of each species within the community. The biodiversity index can be a benchmark (indicator) of an ecosystem. Can be measured whether included into new, medium, or old. Young ecosystems mean that within the ecosystem newly grown or formed some dominating organisms. Old ecosystems have a sense that these ecosystems have long been formed and interactions that occur therein already exist and are arranged in such a complex. While Ecosystems are meaningful that these ecosystems have long been formed but due to the high stress factors that affect the change in the condition of organism interaction becomes decreased because of vulnerability to these factors.

\section{Conclusion}

Based on research result: The data obtained were 12 mangrove species in the study sites, namely 7 mangroves namely Avicennia alba, Avicennia officinalis, Bruguiera sexangula, Exoecaria agallocha, Nypa fructicans, Rhizopora apiculata, Rhizopora mucronata and 5 mangrove followed by Acanthus ilicifolius, Acrostichum aureum, Morinda citrifolia, Hibiscus tilliaceus, Plucea indica. Analysis of observations on mangrove species found was that Avicennia alba species can adapt to salinity between $26-28 \%$ with dissolved oxygen content between 4.7 - $5.8 \mathrm{mg} / \mathrm{L}$. This may indicate that this species has the most widespread adaptability to salinity and dissolved oxygen compared to other species. That's why Avicennia is suspect in all stations. For the Avicennia officinalis species and Rhizopora sp species it can adapt to salinity between $26-27 \%$ and dissolved oxygen content between $5.4-5.8 \mathrm{mg} / \mathrm{L}$ found in station III alone. This indicates environmental and natural factors both biotic and abiotic greatly affect the growth of mangroves. Mangrove is very sensitive to salinity. 
Various mangroves overcome salinity levels in different ways. Some of them are selectively able to avoid salt absorption from the growing medium. While, some others are able to remove salt from a special gland on its leaves.

\section{References}

[1] Brower JE, Zar JH, E. von C. (1990) Field and Laboratory Methods for General Ecology Dubuqe. WCB Publishers.

[2] Noor, Y, R., Khazali, M., S. (1999) Panduan pengenalan mangrove di Indonesia. Bogor: Ditjen PKA : Wetlands International-Indonesia Programme. 